\title{
PERANCANGAN DAN REALISASI DUAL-BAND BAND-STOP FILTER DENGAN METODE SPURLINE DAN STEPPED- IMPEDANCE RESONATOR PADA FREKUENSI 2.45 GHZ DAN 5.8 GHZ
}

\author{
Ananda Dana Pratama ${ }^{1}$, Elisma $^{2}$ \\ 1,2Jurusan Teknik Elektro, Politeknik Negeri Bandung, Bandung 40012 \\ ${ }^{1}$ E-mail : ananda.dana.tcom417@polban.ac.id \\ ${ }^{2}$ E-mail : elisma@polban.ac.id
}

\begin{abstract}
ABSTRAK
Dengan teknologi telekomunikasi wireless, masyarakat mendapatkan kemudahan dalam berkomunikasi, tanpa perlu menggunakan dan instalasi kabel untuk berkomunikasi. Dengan seiring berjalannya waktu, jumlah pengguna teknologi yang semakin bertambah menyebabkan pengelolaan frekuensi menjadi terbatas. Trafik yang padat tersebut dapat menimbulkan noise dan interferensi pada operasi perangkat lainnya yang dapat merugikan pihak lain. Dengan demikian, diperlukan penghalang sinyal gelombang mikro dengan frekuensi tertentu. Untuk itu, pada makalah ini dirancang dan direalisasikan sebuah dual-band band-stop filter dengan menggunakan metode spurline dan steppedimpedance resonator. Filter tersebut dapat memblokir sinyal pada frekuensi $2.45 \mathrm{GHz}$ dan $5.8 \mathrm{GHz}$ dengan nilai return loss kurang dari $5 \mathrm{~dB}$ dan insertion loss lebih dari $20 \mathrm{~dB}$. Bahan substrat yang digunakan adalah rogers 5880 yang memiliki ketebalan $1.57 \mathrm{~mm}$ dan konstanta dielektrik 2.2. Dimensi fisik filter mikrostrip yang berhasil direalisasi memiliki ukuran bernilai $2 \times 6.95 \mathrm{~cm}$. Dari hasil pengukuran filter di lab, didapatkan nilai frekuensi tengah yang masing-masing bernilai $2.53 \mathrm{GHz}$ dan $5.95 \mathrm{GHz}$, insertion loss pada frekuensi tengah masing-masing bernilai $15.52 \mathrm{~dB}$ dan $15.79 \mathrm{~dB}$, return loss pada frekuensi tengah masing-masing bernilai $2.52 \mathrm{~dB}$ dan $2.48 \mathrm{~dB}$, dan bandwidth masing masing bernilai $157.05 \mathrm{MHz}$ dan $221.67 \mathrm{MHz}$.
\end{abstract}

\section{Kata Kunci}

Band-stop filter, dual-band, spurline, stepped-impedance resonator, insertion loss, return loss

\section{PENDAHULUAN}

Perusahaan telekomunikasi di era globalisasi saat ini semakin berkembang seiring dengan pesatnya kebutuhan komunikasi. Teknologi telekomunikasi yang maju memberikan kemudahan kepada masyarakat untuk melakukan aktivitas komunikasi dan dapat meminimalisir biaya yang dikeluarkan. Perkembangan teknologi telekomunikasi sudah berkembang dari wired network menjadi wireless network. Dengan teknologi wireless, masyarakat menjadi lebih mudah untuk melakukan komunikasi jarak jauh [1].

ISM band merupakan pita frekuensi yang sudah digunakan secara luas di bidang komunikasi, militer, dan sains. Pita frekuensi dari ISM band adalah $2.4 \mathrm{GHz}$ dan $5.8 \mathrm{GHz}$ yang dimana kedua frekuensi tersebut merupakan unlicensed band. Dengan demikian, kedua pita frekuensi tersebut dapat digunakan secara bebas oleh masyarakat yang digunakan untuk mendukung berbagai kegiatan seperti melakukan komunikasi jarak jauh.

Seiring berjalannya waktu, semakin banyak produk komersial atau perangkat yang bekerja pada pita frekuensi tersebut sehingga terjadi peningkatan jumlah pengguna pada pita frekuensi tertentu. Dengan demikian, trafik yang padat terjadi pada pita frekuensi tersebut karena jumlah pengguna yang tinggi dapat menimbulkan yang dapat mengganggu kinerja operasi perangkat lainnya di bidang komunikasi, sains, maupun militer. Masalah lain juga terjadi apabila sinyal yang tidak diinginkan menimbulkan interferensi yang merusak informasi yang ditransmisikan. Dengan demikian sebuah penggunaan filter pada suatu perangkat telekomunikasi wireless, memainkan peran penting dalam menyeleksi ataupun menolak frekuensi tertentu, sehingga interferensi dan noise dapat diminimalisir [2].

Untuk frekuensi rendah, lumped element seperti induktor dan kapasitor digunakan pada desain filter, sedangkan transmission line section dan waveguide elements digunakan pada desain filter untuk frekuensi microwave band-stop filter [3] Salah satu metode yang sering digunakan dalam merancang filter mikrostrip adalah metode Spurline dan Stepped Impedance Resonator. Dengan demikian, digunakan kombinasi kedua metode tersebut untuk perancangan Dual-Band Band-Stop Filter pada frekuensi $2.45 \mathrm{GHz}$ dan $5.8 \mathrm{GHz}$. Kedua metode tersebut merupakan metode sederhana yang memiliki karakteristik dual-band dan bandwidth maksimal $10 \%$ dan dapat meminimalisir nilai dari dimensi fisik. [4] 


\section{DASAR TEORI}

\subsection{Band-Stop Filter}

Band-Stop Filter adalah filter atau penyaring frekuensi yang menolak dan memblokir frekuensi yang berada di antara dua titik cut-off, sedangkan semua frekuensi yang berada di bawah frekuensi tertentu (dibawah titik cut-off) dan semua frekuensi yang berada diatas frekuensi tertentu (diatas titik cut-off) akan dilewatkannya.

\subsection{Spurline}

Spurline merupakan salah satu metode yang digunakan untuk merancang band-stop filter. Pada awalnya, spurline berasal dari bentuk Stripline oleh Shiffman dan Mattahei. Akan tetapi, Bates mengimplementasi stripline tersebut ke dalam bentuk mikrostrip. [5]

Spurline menawarkan bandwidth yang lebih besar dengan perkiraan $10 \%$. Struktur resonan terletak didalam line. Hal ini menyebabkan reduksi pada radiation loss jika dibandingkan dengan desain bandstop dengan menggunakan coupled-lines or stubs. Jika diasumsikan velositi fasa dari even dan odd mode adalah sama, maka open circuit line dapa di persentasikan dengan karakteristik impandsi $Z_{1}$ sedangkan yang satu lagi disebut $Z_{12}$. Panjang dari spur a diperkiraan bernilai $\lambda / 4$ pada midband. Sedangkan gap (b) dikenal sebagai efek friengen field, yang dimana adalah line ekstensi. Sehingga panjang keseluruhan spur adalah:

$$
a=\frac{c}{4 f_{r} \sqrt{\varepsilon_{r e o}}}-\delta l
$$

$\varepsilon_{\text {reo }}$ adalah permitifitas efektif odd mode pada resonansi frekuensi

$$
\delta l=C_{o d d} V_{p o} Z_{o o}
$$

$\mathrm{Z}_{\mathrm{oo}}, \mathrm{v}_{\mathrm{po}}$ and $\mathrm{C}_{\mathrm{odd}}$ adalah impedansi karakteristik, fase velocity, dan kapasitansi dari odd mode. $Z_{o o}$ didapatkan dari $Z_{1}$ dan $Z_{12}$, sedangkan $C_{o o}$ dapat ditemukan dari grafik yang ditunjukkan pada gambar ketika perbandinngan $\mathrm{W} / \mathrm{h}$ adalah 1

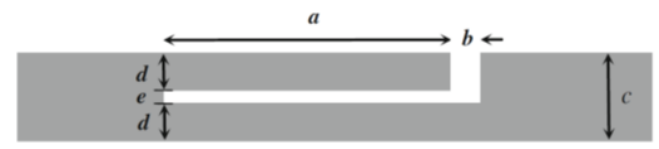

Gambar 1. Konfigurasi Spurline [5]

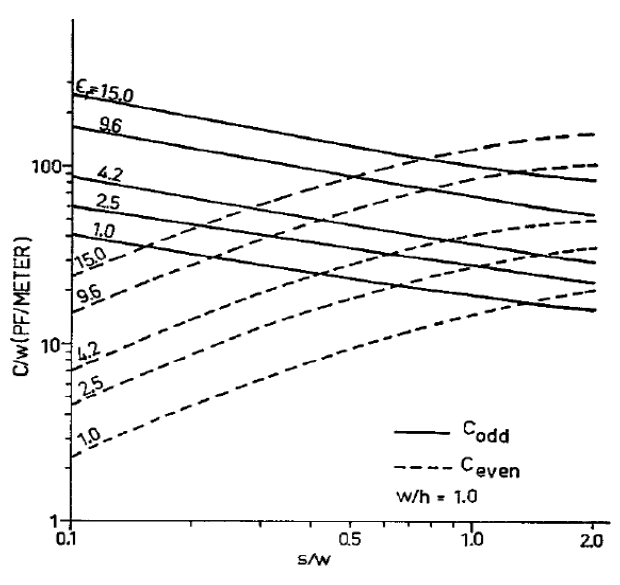

Gambar 2. Grafik $\mathrm{C}_{\text {even }}$ dan $\mathrm{C}_{\text {odd }}$ per unit lebar dengan nilai kontansta dielektrik dari 1 sampai dengan 15. [6]

\subsection{Stepped-Impedance Resonator}

Stepped Impedance Resonator (SIR) merupakan resonator yang berupa saluran mikrostrip yang dapat menghasilkan dual band pada filter dengan ukuran resonator yang dapat diubah agar menghasilkan ukuran dimensi filter yang kecil. Saluran mikrostrip pada SIR memiliki struktur seperti pada umumnya saluran mikrostrip yang terdiri dari bidang tanah dan konduktor strip dipisahkan oleh subtrat dielektrik dengan konstanta dielektrik [7]. Bentuk dasar SIR saat $\lambda \mathrm{g} / 2$ dapat ditunjukkan pada Gambar II.12.

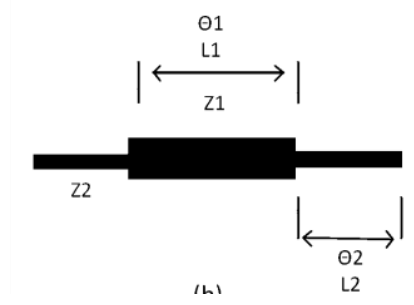

Gambar 3. Bentuk dasar stepped impedance resonator

Nilai dimensi dari induktor dan kapasitor pada rangkaian lumped element dapat di konversi menjadi transmisi lines. Induktor dapat diganti dengan menggunakan short-circuit stub dengan bernilai $\beta l$ dan impedansi karakteristik L. Sedangkan kapasitor juga dapat diganti dengan menggunakan open-circuit stub yang bernilai $\beta l$ dan impedansi karakteristik 1/C. Persamaan dibawah adalah persamaan untuk mendapatkan nilai $\beta l$. [8]

$$
\begin{gathered}
Z_{\text {in }}=j Z_{h} \tan \beta l=j \omega L^{\prime} \\
Z_{\text {in }}=-j Z_{l} \cot \beta l=-j \frac{1}{\omega C^{\prime}}
\end{gathered}
$$

\subsection{Parameter Pengukuran}

Insertion loss atau IL adalah rugi sisipan yang dapat menunjukkan ukuran keefektifan sebuah filter. Untuk band-stop filter, semakin besar nilai IL, semakin bagus band-stop filter dalam menghalau sinyal [9]. Selanjutnya adalah return loss atau RL yang merupakan 
parameter yang digunakan untuk mengetahui berapa banyak daya yang hilang dan daya yang kembali sebagai pantulan [10]. Parameter selanjutnya adalah Frekuensi tengah merupakan ukuran frekuensi yang memiliki nilai IL yang paling besar sehingga menjadi pusat diantara frekuensi cutoff atas dan bawah Lebar pita frekuensi yang dibatasi frekuensi cutoff dikenal dengan bandwidth. Untuk mengetahui bandwidth dapat menggunakan persamaan dibawah ini. [9]

$$
\mathrm{BW}=\mathrm{f}_{1}-\mathrm{f}_{2}
$$

\section{METODOLOGI PELAKSANAAN}

\subsection{Spesifikasi Dual-Band Band-Stop Filter}

Terdapat spesifikasi yang diharapkan dari hasil realisasi dual-band band-stop yang terukur yang ditunjukkan oleh tabel 1.

Tabel 1. Spesifikasi Band-Stop Filter yang diharapkan

\begin{tabular}{|c|c|}
\hline Parameter & Nilai \\
\hline Frekuensi Tengah & $\begin{array}{l}\mathrm{f}_{01}=2450 \mathrm{MHz} \\
\mathrm{f}_{02}=5800 \mathrm{MHz}\end{array}$ \\
\hline $\begin{array}{c}\text { Toleransi Frekuensi } \\
\text { Tengah }\end{array}$ & $\begin{array}{l}5 \% \text { dari frekuensi } \\
\text { tengah }\end{array}$ \\
\hline Bandwidth & $\begin{array}{l}\text { Maksimal } 10 \% \text { dari } \\
\text { frekuensi tengah }\end{array}$ \\
\hline Insertion Loss (IL) & $\geq 20 \mathrm{~dB}$ \\
\hline Return Loss (RL) & $\approx 0 \mathrm{~dB}$ \\
\hline
\end{tabular}

Terdapat juga spesifikasi bahan substrat bandstop filter yang akan digunakan yaitu Rogers 5880 adalah konstanta dielektrik bernilai 2.2. dielektrik loss tangen bernilai 0.0009 , dan ketebalan dielektrik bernilai $1.57 \mathrm{~mm}$

\subsection{Perancangan}

\subsubsection{Spurline}

Spurline memiliki beberapa nilai dimensi fisik yang harus ditetapkan untuk mendapatkan spesifikasi yang sudah ditentukan. Cara yang digunakan untuk menentukan dimensi fisik spurline adalah dengan cara trial \& error. Cara tersebut merupakan cara dimana melakukan pengujian pada setiap perubahan nilai dimensi fisik dan melakukan optimasi hingga mendapatkan nilai error yang paling minimal.

Nilai-nilai dimensi fisik spurline dapat ditentukan berdasarkan nilai $\mathrm{W}$ feedline yang sudah diperhitungkan. Nilai dimensi dari L, $\Delta \mathrm{L}, \mathrm{S}, \mathrm{W} 1$ dan W2 diatur sedemikian rupa hingga mendapatkan respon frekuensi yang sesuai dengan spesifikasi yang sudah ditentukan. Berdasarkan percobaan, perubahan nilai dimensi fisik dari $\mathrm{L}$ dan $\Delta \mathrm{L}$, berpengaruh pada nilai frekuensi tengah. Sedangkan untuk perubahan nilai $\mathrm{S}$, W1, dan W2 berpengaruh pada bandwidth dan frekuensi cut-off. Setelah dilakukan percobaan, ditetapkan nilai dimensi fisik spurline yang menghasilkan respon frekuensi yang sesuai dengan spesifikasi yang diharapkan yang ditunjukkan oleh tabel 2 .

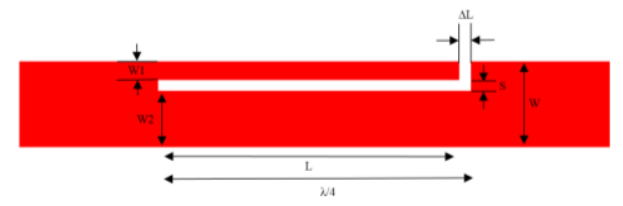

Gambar 4. Bentuk fisik metode spurline dilihat dari sisi atas

Tabel 2. Dimensi Fisik Band-Stop Filter Metode Spurline

\begin{tabular}{c|c}
\hline \multicolumn{2}{|c}{ Spurline } \\
\hline Parameter & Nilai (mm) \\
\hline $\mathrm{W}$ & 4.838 \\
\hline $\mathrm{W} 1$ & 0.254 \\
\hline $\mathrm{W} 2$ & 4.33 \\
\hline $\mathrm{S}$ & 0.254 \\
\hline$\Delta \mathrm{L}$ & 0.254 \\
\hline $\mathrm{L}$ & 22.775 \\
\hline
\end{tabular}

\subsubsection{Stepped-Impedance Resonator}

Perancangan metode stepped-impedance resonator dilakukan dengan beberapa tahap, yaitu dimulai dengan merancang prototipe lumped element sirkuit dari low-pass filter, melakukan transformasi lowpass filter menjadi band-stop filter, mengubah lumped element menjadi mikrostrip line, dan melakukan optimasi dengan fitur yang disediakan oleh aplikasi Advance Design System 2020.

Untuk mendapatkan nilai bandwidth yang lebih kecil, nilai dimensi fisik dari mikrostrip line yang didapatkan dari optimass, digunakan untuk menyusun stepped-impedance resonator hairpin. Penentuan jumlah hairpin yang akan digunakan menjadi bagian dari perancangan SIR. Jumlah hairpin berpengaruh pada bandwidth. Desain SIR hairpin diletakkan bersebelahan dengan jalur feedline dengan gap yang sudah ditentukan.

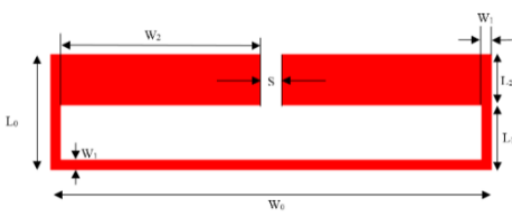

Gambar 5. Bentuk fisik metode stepped-impedance resonator hairpin dilihat dari sisi atas

Tabel 3. Dimensi fisik stepped impedance resonator hairpin

\begin{tabular}{c|c}
\hline Parameter & Nilai(mm) \\
\hline $\begin{array}{c}\text { Jarak antar hairpin } \\
(\mathrm{G})\end{array}$ & 11.124 \\
\hline $\begin{array}{c}\text { Jarak antara hairpin } \\
\text { dengan feeder }(\Delta \mathrm{G})\end{array}$ & 0.5 \\
\hline L0 & 2.167 \\
\hline L1 & 0.765 \\
\hline L2 & 1.402 \\
\hline W0 & 7.936 \\
\hline W1 & 0.254 \\
\hline W2 & 3.564 \\
\hline S & 0.3
\end{tabular}




\subsubsection{Penggabungan Metode Spurline dan Stepped- Impedance Resonator}

Langkah selanjutnya setelah menetapkan nilai akhir dari dimensi fisik untuk kedua metode adalah proses penggabungan untuk menghasilkan sifat dualband pada filter. Proses penggabungkan yang dilakukan adalah menempatkan kedua metode tersebut di dalam satu garis feeder yang sama seperti yang ditunjukkan pada gambar 6

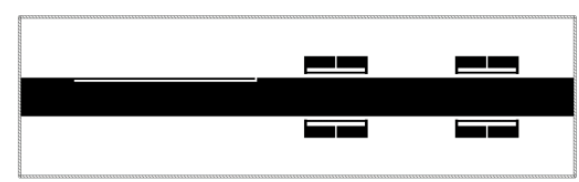

Gambar 6. Bentuk fisik dual-band band-stop filter metode spurline dan stepped-impedance resonator

\subsection{Simulasi}

Langkah selanjutnya setelah semua persiapan simulasi sudah dilakukan adalah melakukan simulasi respon frekuensi dari perancangan dual-band band-stop filter dengan menggunakan aplikasi Advanced Design System 2020.

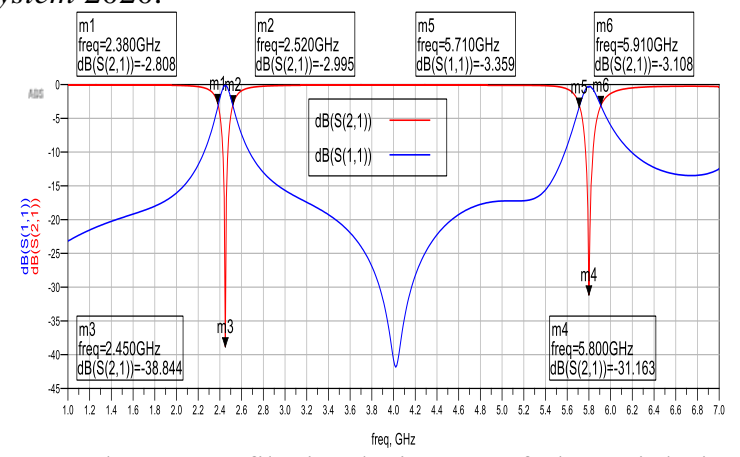

Gambar 7. Grafik simulasi respon frekuensi dari perancangan dual-band band-stop filter

Tabel 4. Spesifikasi pada simulasi dual-band band-stop

\begin{tabular}{c|c}
\multicolumn{2}{c}{ filter } \\
\hline Parameter & Nilai \\
\hline Frekuensi Cut Off & $\mathrm{f}_{\mathrm{c} 11}=2.39$ \\
Bawah $(\mathrm{GHz})$ & $\mathrm{f}_{\mathrm{c} 12}=2.52$ \\
\hline Frekuensi Cut Off Atas & $\mathrm{f}_{\mathrm{c} 21}=5.72$ \\
$(\mathrm{GHz})$ & $\mathrm{f}_{\mathrm{c} 22}=5.92$ \\
\hline Frekuensi Tengah & $\mathrm{f}_{01}=2.45$ \\
$(\mathrm{GHz})$ & $\mathrm{f}_{02}=5.8$ \\
\hline \multirow{2}{*}{ Insertion Loss $(\mathrm{dB})$} & $\mathrm{IL}_{1}=38.84$ \\
\hline \multirow{2}{*}{ Return Loss $(\mathrm{dB})$} & $\mathrm{IL}_{2}=31.16$ \\
\hline
\end{tabular}

\subsection{Realisasi}

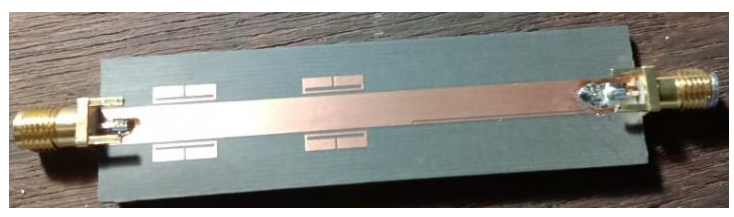

Gambar 8. Realisasi Dual-Band Band-Stop Filter
Setelah mendapatkan hasil simulasi yang memenuhi spesifikasi yang diharapkan, layout dualband band-stop filter tersebut direalisasikan ke sebuah PCB. Layout tersebut di eksport dari software Advance Design System 2020 dalam bentuk gerber file dan di import ke dalam software Eagle Autodesk untuk membuat garis tepi pada layout filter. Fungsi garis tepi adalah untuk memberikan informasi ukuran yang akan dicetak kepada jasa cetak PCB. Karena keterbatasan ukuran PCB Rogers 5880 yang tersedia, maka ukuran yang akan dicetak adalah $6.95 \times 2 \mathrm{~cm}$. Setelah diberi garis tepi, file layout tersebut di export menjadi file $\mathrm{dxf}$ oleh software Eagle Autodesk. di berikan ke pada pihak jasa cetak PCB beserta dengan bahan PCB Rogers 5880.

\section{PENGUJIAN DAN ANALISIS}

\subsection{Pengujian}

Setelah dilakukan proses realisasi, tahap selanjutnya adalah pengujian dari realisasi filter yang telah di buat. Tujuan dari pengukuran ini adalah mendapatkan data-data yang diperlukan yang nantinya akan dibandingkan dengan spesifikasi yang telah ditentukan dari hasil simulasi sebelumnya pada aplikasi Advanced Design System 2020. Pengukuran dilakukan dengan menggunakan Anritsu Shockline Economy Network Analyzer MS46322A

Tabel 5. Spesifikasi pada pengukuran dual-band band-

\begin{tabular}{c|c}
\multicolumn{2}{c}{ stop filter } \\
\hline Spesifikasi & Pengukuran \\
\hline \multirow{3}{*}{ Frekuensi Stop $(\mathrm{GHz})$} & $\mathrm{f}_{\mathrm{c} 11}=2.45$ \\
& $\mathrm{f}_{\mathrm{c} 12}=2.53$ \\
$\mathrm{f}_{\mathrm{c} 21}=5.84$ \\
$\mathrm{f}_{\mathrm{c} 22}=5.06$ \\
\hline \multirow{2}{*}{ Bandwidth -3dB $(\mathrm{MHz})$} & $\mathrm{BW}_{1}=157.05$ \\
\hline \multirow{2}{*}{ Frekuensi Tengah $(\mathrm{Ghz})$} & $\mathrm{BW}_{2}=221.67$ \\
\hline \multirow{2}{*}{ Insertion Loss $(\mathrm{dB})$} & $\mathrm{f}_{01}=2.53$ \\
\hline \multirow{2}{*}{ Return Loss $(\mathrm{dB})$} & $\mathrm{f}_{02}=5.95$ \\
\hline
\end{tabular}

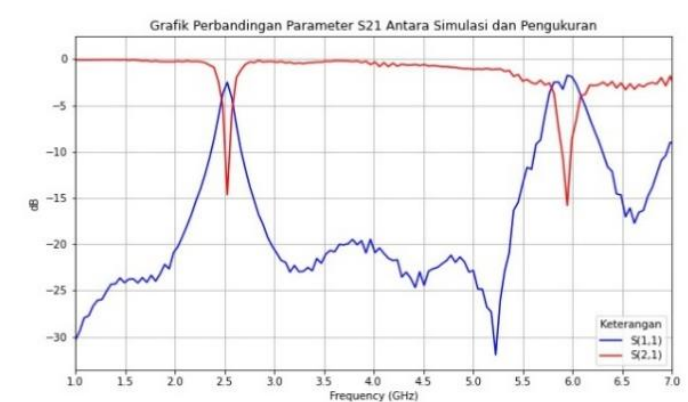

Gambar 9. Grafik Hasil Pengukuran Return Loss dan Insertion Loss

Tabel 6 merupakan data data simulasi dan pengukuran yang disajikan dalam bentuk tabel. Tabel 
ini berfungsi sebagai pembanding pada setiap spesifikasi yang didapatkan.

Tabel 6. Perbandingan antara hasil simulasi dan
pengukuran

\begin{tabular}{c|c|c}
\hline Spesifikasi & Simulasi & Pengukuran \\
\hline & $\mathrm{f}_{\mathrm{c} 11}=2.39$ & $\mathrm{f}_{\mathrm{c} 11}=2.45$ \\
Frekuensi & $\mathrm{f}_{\mathrm{c} 12}=2.52$ & $\mathrm{f}_{\mathrm{c} 12}=2.53$ \\
Stop $(\mathrm{GHz})$ & $\mathrm{f}_{\mathrm{c} 21}=5.72$ & $\mathrm{f}_{\mathrm{c} 21}=5.84$ \\
& $\mathrm{f}_{\mathrm{c} 22}=5.92$ & $\mathrm{f}_{\mathrm{c} 22}=5.06$ \\
\hline Bandwidth & $\mathrm{BW}_{1}=135$ & $\mathrm{BW}_{1}=157.05$ \\
$-3 \mathrm{~dB}(\mathrm{MHz})$ & $\mathrm{BW}_{2}=200$ & $\mathrm{BW}_{2}=221.67$ \\
\hline Frekuensi & $\mathrm{f}_{01}=2.45$ & $\mathrm{f}_{01}=2.53$ \\
Tengah $(\mathrm{Ghz})$ & $\mathrm{f}_{02}=5.8$ & $\mathrm{f}_{02}=5.95$ \\
\hline Insertion & $\mathrm{IL}_{1}=38.84$ & $\mathrm{IL}_{1}=14.5$ \\
Loss $(\mathrm{dB})$ & $\mathrm{IL}_{2}=31.16$ & $\mathrm{IL}_{2}=15.79$ \\
\hline Return Loss & $\mathrm{RL}_{1}=0.11$ & $\mathrm{RL}_{1}=2.52$ \\
$(\mathrm{~dB})$ & $\mathrm{RL}_{2}=0.39$ & $\mathrm{RL}_{2}=2.48$ \\
\hline
\end{tabular}

\subsection{Analisis}

Berdasarkan tabel 6, terdapat perbedaan frekuensi tengah antara hasil simulasi dan hasil simulasi. Pada hasil simulasi, nilai frekuensi tengah yang didapatkan adalah $2.45 \mathrm{GHz}$ dan $5.8 \mathrm{GHz}$ yang dimana hasil simulasi tersebut sesuai dengan spesifikasi yang diinginkan. Sedangkan pada hasil pengukuran, nilai frekuensi tengah yang didapatkan adalah $2.53 \mathrm{GHz}$ dan $5.95 \mathrm{GHz}$. Berdasarkan spesifikasi yang diharapkan, nilai frekuensi tengah memiliki nilai toleransi bernilai maksimal 5\%. Dengan demikian, nilai frekuensi tengah pada hasil pengukuran memiliki persentase $3.24 \%$ untuk frekuensi pertama dan $2.58 \%$ untuk frekuensi kedua. Dari nilai persentase yang didapatkan tersebut membuktikan bahwa nilai frekuensi stop yang didapatkan sesuai dengan spesifikasi yang didapatkan. Pergesaran frekuensi tengah tersebut disebabkan oleh perubahan nilai konstanta dielektrik. Berdasarkan percobaan yang sudah dilakukan, semakin kecil nilai konstanta dielektrik maka nilai frekuensi tengah akan bergesar kekanan. Sehingga, dari hasil frekuensi tengah pada pengukuran menunjukkan bahwa nilai konstanta dielektrik pada bahan rogers 5880 adalah kurang dari 2.2. Nilai konstanta dielektrik yang tidak sesuai disebabkan adanya nilai toleransi sebesar 0.2 yang dicantumkan pada datasheet Rogers 5880 .

Nilai bandwidth yang didapatkan pada hasil simulasi adalah $135 \mathrm{Mhz}$ dan $200 \mathrm{MHz}$. Nilai bandwidth tersebut sudah memenuhi nilai spesifikasi yang diharapkan yaitu dimana nilai bandwidth yang diharapkan memiliki nilai maksimal $245 \mathrm{MHz}$ dan 580 MHz. Sedangkan pada hasil pengukuran, nilai bandwidth yang didapatkan adalah $157.05 \mathrm{MHz}$ dan 221.67 MHz. Sehingga nilai bandwidth pada hasil pengukuran sudah memenuhi hasil pengukuran.

Nilai insertion loss pada frekuensi tengah pada spesifikasi yang diharapkan memiliki nilai lebih dari 20 dB. Nilai insertion loss ini menunjukkan kualitas filter dalam meredam atau menghilangkan sinyal RF pada frekuensi tengah yang diharapakan. Pada hasil simulasi, nilai insertion loss yang didapatkan adalah $38.84 \mathrm{~dB}$ pada frekuensi pertama dan $31.16 \mathrm{~dB}$ pada frekuensi kedua. Berdasarkan kedua nilai insertion loss yang didapatkan dari simulasi, nilai insertion loss tersebut sudah memenuhi spesifikasi yang diharapkan karena memiliki nilai lebih dari $20 \mathrm{~dB}$. Sedangkan pada hasil pengukuran, nilai insertion loss yang didapatkan adalah $14.51 \mathrm{~dB}$ dan $15.79 \mathrm{~dB}$. Nilai insertion loss tersebut belum memenuhi spesifikasi yang diharapkan. Sedangkan untuk nilai return loss yang dimana menunjukkan kualitas filter dalam memantulkan sinyal. Semakin kecil nilai return loss, maka nilai pantul dari filter tersebut semakin besar. Nilai return loss pada spesifikasi yang diharapkan memiliki nilai kurang dari $5 \mathrm{~dB}$. Berdasarkan nilai return loss yang didapatkan dari hasil simulasi yaitu $0.11 \mathrm{~dB}$ dan $0.39 \mathrm{~dB}$, nilai tersebut sudah memenuhi spesifikasi yang diharapkan. Sedangkan pada hasil pengukuran, nilai insertion loss yang didapatkan memiliki nilai masing-masing $2.52 \mathrm{~dB}$ dan $2.48 \mathrm{~dB}$. Nilai tersebut menunjukkan bahwa return loss dari hasil pengukuran sudah memenuhi spesifikasi yang diharapkan.

Berdasarkan perbandingan nilai insertion loss dan return loss, terdapat perbedaan yang cukup signifikan. Perbedaan yang terjadi disebabkan oleh faktor proses realisasi, proses soldering, temperatur pada filter, konektor yang digunakan, dan kabel yang digunakan. Faktor - faktor tersebut yang menyebabkan filter yang sudah direalisasi tidak mampu memiliki kualitas sebagai penghalang sinyal yang sama dengan simulasi.

\section{KESIMPULAN}

Berdasarkan proses perancangan dan realisasi filter secara keseluruhan dapat disimpulkan bahwa

1. Pada hasil pengukuran dual-band band-stop filter, didapatkan frekuensi stop dengan rentang frekuensi $2.45 \mathrm{GHz}$ sampai dengan $2.53 \mathrm{GHz}$ untuk band frekuensi pertama dan rentang frekuensi $5.84 \mathrm{GHz}$ dan $5.06 \mathrm{GHz}$

2. Didapatkan spesifikasi dari filter dimana nilai frekuensi tengah masing-masing bernilai $2.53 \mathrm{GHz}$ dan $5.95 \mathrm{GHz}$, insertion loss pada frekuensi tengah masing-masing bernilai $14.52 \mathrm{~dB}$ dan $15.79 \mathrm{~dB}$, return loss pada frekuensi tengah masing-masing bernilai $2.52 \mathrm{~dB}$ dan $2.48 \mathrm{~dB}$, dan bandwidth masing masing bernilai $157.05 \mathrm{MHz}$ dan 221.67 $\mathrm{MHz}$.

3. Dari data pengukuran, terdapat spesifikasi yang tidak memenuhi spesifikasi yang diharapkan yaitu nilai insertion loss yang kurang dari $20 \mathrm{~dB}$ pada kedua band frekuensi stop. Faktor yang menyebabkan ketidaksesuaian antara hasil pengukuran dan perancangan disebabkan oleh redaman dari konektor, redaman akibat miss match, faktor realisasi, dan ukuran bahan PCB yang tidak sesuai. 
4. Filter yang berhasil direalisasikan memiliki nilai dimensi fisik mikrostrip dengan ukuran $2 \times 6.95 \mathrm{~cm}$.

\section{DAFTAR PUSTAKA}

[1] L. C. Dewi, "WIRELESS TECHNOLOGY DEVELOPMENT: HISTORY, NOW, AND THEN," ComTech, vol. 2, no. 2, pp. 1224-1240, 2011.

[2] S. Ariyanti and L. P. Arif, "EVALUASI PEMANFAATAN FREKUENSI 2.4 GHz DALAM PENYELENGGARAAN INTERNET WIRELESS," Buletin Pos dan Telekomunikasi, vol. 9, no. 3, pp. 293315, 2011.

[3] S. Mumtaz, "Spurious response elimination techniques for microwave low pass and band pass filter," Universitas Sains Malaysia, 2005.

[4] H. G. S. Alrwuili, "Dual-Band Bandstop Filter (Dbbsf) Using Spurline \& Stepped-Impedance Resonator With Tunable Devices," University of Colorado Colorado Springs , 2018.

[5] Z. Awang, Microwave Systems Design, Singapore: Springer Singapore, 2014.

[6] R. Bates, "Design of microstrip spur-line band-stop filters," MICROWAVES, OPTICS AND ACOUSTICS, vol. 1, no. 6, pp. 209-214, 1977.

[7] K. Xu, "Novel Design Of A Compact Triple-Band Bandpass Filter Using Short Stub-Loaded JSirs And Embedded Sirs Structure," Progress In Electromagnetics Research, vol. 142, p. 309, 2013.

[8] R. E. Collin, Foundations for Microwave Engineering, New York: The Institute of Electrical and Electronics Engineers, 2001.

[9] F. Sahala and E. Sulaeman, "Perancangan dan Simulasi Bandpass Filter untuk Aplikasi IF Radar Coastal pada Frekuensi $500 \mathrm{MHz}-700 \mathrm{MHz}$," Prosiding The 11th Industrial Research Workshop and National Seminar, pp. 13-19, 2020.

[10] E. Sulaeman, "Filter Gelombang Mikro," in HF \& Gelombang Mikro, Bandung, Politeknik Negeri Bandung, 2007, pp. 1-10. 